\title{
Predictors of 2 year outcomes of juvenile idiopathic arthritis in a multicenter Canadian cohort: the ReACCh out experience
}

\author{
Natalie J Shiff ${ }^{*}$, Kiem G Oen${ }^{7}$, Jaime Guzman ${ }^{6}$, Nicole A Johnson ${ }^{1}$, Adam Huber ${ }^{4}$, Shirley Tse ${ }^{3}$, Lori B Tucker ${ }^{2}$, \\ Rae SM Yeung ${ }^{3}$, Ciaran M Duffy ${ }^{1}$, ReACCh Out Investigators ${ }^{5}$
}

From 2011 Pediatric Rheumatology Symposium sponsored by the American College of Rheumatology Miami, FL, USA. 2-5 June 2011

\section{Purpose}

The ability to predict which children with Juvenile idiopathic Arthritis (JIA) are likely to have worse outcomes would allow a more targeted aggressive approach to initial therapy. We used data from the Research on Arthritis in Canadian Children Emphasizing Outcomes (ReACCh Out), a 16-centre prospective inception cohort of children with newly diagnosed JIA, to identify predictors of 2-year outcomes present during the first 6 months after enrollment.

\section{Methods}

Data was available on 223 to 291 children depending on the analysis. The 2-year clinical outcomes were remission, a Childhood Health Assessment questionnaire (CHAQ) score of $\geq 0.75$, and the Juvenile Arthritis Quality of Life Questionnaire (JAQQ) score. Remission was defined according to Wallace criteria (without ESR or CRP), and combined patients on and off medication. The candidate predictors listed in Table 1 were selected for their clinical relevance and forced in a stepwise manner into regression models. They underwent natural logarithmic transformation ( $\mathrm{Ln}$ ) if not normally distributed. Logistic regression was used for prediction of remission and CHAQ outcomes, and linear regression for the JAQQ score.

\section{Results}

Table 1 shows results of the regression models. The only significant independent predictor of remission at both month 0 and 6 was the number of active joints, but $\mathrm{R}^{2}$ was low (0.06 and 0.09 at month 0 and month 6 respectively). A CHAQ score $\geq 0.75$ was a strong independent predictor of a high 24-month CHAQ at month 0 but not at month 6 ( $\mathrm{R}^{2}$ of 0.22 and 0.24 respectively). The JAQQ score at both month 0 and month 6 was the only significant independent predictor of the 24 month JAQQ score ( $\mathrm{R}^{2}$ of 0.09 and 0.23 respectively). There was a non-statistically significant trend for rheumatoid factor positivity to be associated with lesser chance of remission and CHAQ score $\geq 0.75$ at 24 months.

\section{Conclusion}

As hypothesized, most measures at 6 months were better than the baseline measures at predicting 2 year outcomes. Interestingly, $\mathrm{CHAQ}$ score at baseline seemed a better predictor of 2 year outcome than CHAQ score at 6 months. Although only a single variable was a significant independent predictor of the outcomes in each model, all 3 models explained a larger proportion of variation in the outcome when the additional variables were included. These results highlight the relatively limited ability to predict disease course at early stage of disease, and should act as an impetus for further research into relevant clinical and biochemical markers of outcome.

\section{Disclosure}

Natalie J. Shiff: None; Kiem G. Oen: None; Jaime Guzman: None; Nicole A. Johnson: None; Adam Huber: None; Shirley Tse: None; Lori B. Tucker: None; Rae S. M. Yeung: None; Ciaran M. Duffy for the ReACCh Out Investigators: None.

${ }^{8}$ University of Saskatchewan, Saskatoon, SK, Canada

Full list of author information is available at the end of the article

(c) 2012 Shiff et al; licensee BioMed Central Ltd. This is an Open Access article distributed under the terms of the Creative Commons Attribution License (http://creativecommons.org/licenses/by/2.0), which permits unrestricted use, distribution, and reproduction in any medium, provided the original work is properly cited. 
Table 1 Resuts of regression models using basline and 6 month variables to predict 24 month remision, CHAQ $\geq 0.75$, and JAQQ score.

\begin{tabular}{|c|c|c|c|c|c|}
\hline Outcome at month 24 & $\mathrm{~N}$ & Regression & Candidate predictor & OR or $\beta$ at month $0(95 \% \mathrm{Cl})$ & OR or $\beta$ at month $6(95 \% \mathrm{Cl})$ \\
\hline \multirow[t]{5}{*}{ Remission } & 223 & Logistic & Ln (number of active joints) & $0.72(0.55,0.95)$ & $0.63(0.47,0.85)$ \\
\hline & & & RF & $0.52(0.14,2.00)$ & $0.51(0.13,1.99)$ \\
\hline & & & $\operatorname{Ln}(\mathrm{CHAQ} \text { at month } 0)^{*}$ & $0.61(0.33,1.12)$ & $0.49(0.25,0.98)$ \\
\hline & & & Ln (onset to first visit) ${ }^{\S}$ & $0.92(0.68,1.25)$ & $0.92(0.67,1.26)$ \\
\hline & & & Ln (age of onset) ${ }^{\#}$ & $1.07(0.76,1.51)$ & $1.16(0.82,1.64)$ \\
\hline \multirow[t]{5}{*}{$C M A Q \geq 0.75$} & 291 & Logistic & $\mathrm{CHAQ} \geq 0.75$ at momth 0 & $7.47(2.48,22.46)$ & $2.17(0.68,6.89)$ \\
\hline & & & Ln (number of active joints )* & $1.02(0.72,7.43)$ & $1.25(0.87,1.78)$ \\
\hline & & & RF & $2.14(0.67,6.66)$ & $2.38(0.72,7.92)$ \\
\hline & & & Ln (JAQQ at month 0) & $1.56(0.34,7.10)$ & $2.38(0.73,7.75)$ \\
\hline & & & Interaction JAQQ x CHAQQ & $1.04(0.90,1.21)$ & $1.22(0.94,1.59)$ \\
\hline \multirow[t]{6}{*}{$\overline{J A Q Q}$} & 270 & Linear & Ln (JAWW at month 0) & $0.34(0.02,0.78)$ & $0.75(0.42,1.07)$ \\
\hline & & & Ln (CHAQ at month 0$)^{*}$ & $0.43(-0.06,0.92)$ & $-0.12(-0.64,0.26)$ \\
\hline & & & RF & $-0.05(-0.60,0.50)$ & $-0.10(-0.58,0.38)$ \\
\hline & & & Ln (age of onset) ${ }^{\#}$ & $0.12(-0.05,0.28)$ & $0.00(-0.15,0.15)$ \\
\hline & & & Enthesitis" & $0.01(-0.35,0.38)$ & $-0.04(-0.41,0.33)$ \\
\hline & & & Interaction JAQQ $\times$ CHAQQ & $-0.01(-0.09,0.07)$ & $0.15(0.05,0.26)$ \\
\hline
\end{tabular}

*0.5 was added to variable prior to Ln transformation

$\S$ time in months

\# age in years

" by history or physical exam

\section{Author details}

${ }^{1}$ Alberta Children's Hospital, Calgary, AB, Canada. ${ }^{2} \mathrm{BC}$ Childrens Hospital, Vancouver, BC, Canada. ${ }^{3}$ Hospital for Sick Children, Toronto, ON, Canada. ${ }^{4}$ IWK Health Centre, Halifax, NS, Canada. ${ }^{5}$ Montreal Children's Hospital, Montreal, QC, Canada. ${ }^{6}$ University of British Columbia, Vancouver, BC, Canada. ${ }^{7}$ University of Manitoba, Winnipeg, MB, Canada. ${ }^{8}$ University of Saskatchewan, Saskatoon, SK, Canada.

Published: 13 July 2012

doi:10.1186/1546-0096-10-S1-A40

Cite this article as: Shiff et al:: Predictors of 2 year outcomes of juvenile idiopathic arthritis in a multicenter Canadian cohort: the ReACCh out experience. Pediatric Rheumatology 2012 10(Suppl 1):A40.
Submit your next manuscript to BioMed Central and take full advantage of:

- Convenient online submission

- Thorough peer review

- No space constraints or color figure charges

- Immediate publication on acceptance

- Inclusion in PubMed, CAS, Scopus and Google Scholar

- Research which is freely available for redistribution

Submit your manuscript at www.biomedcentral.com/submit
C Biomed Central 